\title{
Burn infections characteristics: A review
}

\author{
Andra-Luana LAZARESCU ${ }^{1}$, Andreea GROSU-BULARDA ${ }^{1}$, Mihaela-Cristina ANDREI ${ }^{1,2}$, \\ Adrian FRUNZA ${ }^{1,2}$, Sabina GRAMA ${ }^{1}$, Alexandru STOIAN ${ }^{1}$, Florin Vlad HODEA ${ }^{1}$, \\ Dan Aurel IONESCU ${ }^{1}$, Serban Arghir POPESCU ${ }^{1,2}$, Ioan LASCAR ${ }^{1,2}$ \\ ${ }^{1}$ Clinic of Plastic Surgery, Aesthetic and Reconstructive Microsurgery, Clinical Emergency Hospital, \\ Bucharest, Romania
}

2"Carol" Davila University of Medicine and Pharmacy, Bucharest, Romania

\begin{abstract}
Burn injuries are unique in comparison to other types of trauma because of their severity and major systemic impact produced by extensive lesions with disfunctions that can persist even several years after the injury. Multiple complications can occur during burn injury evolution, from which infections are the most severe and the most frequently encountered, requiring adequate diagnosis and treatment. In most burn centers, increased mortality rates associate with severe burn injuries aggravated by the development of sepsis.

There are multiple sources of infections in burned patients: lungs, wounds, catheters, gastrointestinal and urinary tract. Pathogens are often multi-resistant bacteria but also fungi and viruses appear as opportunistic infections.

The main goal is represented by prevention of organ dysfunction development through specific supportive measures that avoid its onset. Early excision of the burn eschar and wound grafting is essential for patient outcome, decreasing duration of hospitalization, infectious risk and mortality. As a principle, antibiotic treatment in burn infectious complications is started empirically, with broad spectrum agents if the results of microbiological cultures are not available and immediately after the antibiogram is available, targeted antibiotic is introduced. De-escalation strategy is promoted in order to prevent antimicrobial resistance: narrow spectrum drugs with proven efficacy on determined germs are administered, avoiding if possible, reserve antibiotics.
\end{abstract}

Keywords: burns, infection, pathogens, burn wound, pneumonia, sepsis, antibiotic therapy

\section{BACKGROUND}

Burns represent a significant public health problem, with high levels of morbidity and mortality, causing each year around 180.000 deaths from a total of $11,000,000$ burn injuries, provoked by various mechanisms, occurring annually worldwide $[1,2]$. The burn injuries can be produced by flame, hot liquids, contact with hot objects, electrocutions, chemicals or radiation and lead to severe tissular damage $[3,4]$.

Almost half a million individuals belonging to the population of the United States of America suffer burns every year, of which 40,000 needing admission, $75 \%$ being treated in a certified burn center. Overall, the yearly burn injury related deaths were 3,275 in 2016 with the leading cause of death being infection. These numbers have been diminished lately due to advances and breakthroughs in modern medicine by providing aggressive fluid resuscitation, effective excision and skin coverage, pulmonary ventilation, rigorous nutritional adaptations, and last but not least, proper infection management [5-7].

Post-burn immunosuppression increases the infectious risk, being a known fact that infections represent 
the most dangerous complications in extensive burns, severely increasing morbidity and mortality. Burn injuries determine abnormalities in the local skin barrier, tissue ischemia, changes in the normal microbiologic flora, disturbing protective factors and severe suppression of humoral and cellular immunity. Disorders of the immune system caused by burn-associated inflammatory processes become more complicated during the progress of the burn disease, having a difficult pathogenesis with complex mechanisms difficult to approach therapeutically. Burn injury determines the activation of the immune system, including both innate and adaptive responses, with different intensity. Severe burns determine systemic inflammatory response syndrome (SIRS) and also sepsis if an infection is associated, which may lead to multiorgan failure $[3,8]$.

The 2017 National Burn Repository Annual Report of American Burn Association ( $A B A$ ), analyzing a total of 208,654 of patients hospitalized in verified burn units for a period of ten years (2008-2017), reported the distribution of complications that have occurred in those burned patients (figure 1). As we can observe, infectious complications are dominant, with pneumonia representing the most often reported complication, urinary tract infection being the second encountered and cellulitis the third [9].

The above-mentioned report also analyzed the association between burn complications and length of mechanical ventilation (figure 2). The study revealed that the complication prevalence rises with length of mechanical ventilation, excepting urinary tract infection, cellulitis and burn wound infections [9]. The longer period of mechanical ventilation is correlated with burn complications as pneumonia and also may represent a severity marker for the burn illness associating with systemic disfunctions(as kidney failure) in critical patients $[9,10]$.
Infectious complications in burn patients occur with a specific dynamic during patient hospitalization, with cutaneous infections encountered early in patient evolution and, in contrast, pneumonia, urinary infections and bloodstream infections are diagnosed later after burn injury and frequently are determined by resistant pathogens (figure 3) [6].

Multi-drug resistance is among the main factors that contribute to the infection perpetuation, as well as to the development of sepsis. Presence of multi drug-resistant (MDR) organisms favor infections of deep burn lesions and then sepsis. An important challenge in burned patients is still represented by the pathogen resistance to regularly administered antibiotics, because only a small number of new antibiotics is under development. Administering antibiotics to which the MDR pathogens are sensible to, empirically, to burned patients, is simply promoting drug resistance, thus the preexisting issue is intensified. According to previous studies, there is an increased risk of sepsis, multiorgan insufficiency and finally death due to longer hospitalization, antibiotic administration and mechanical ventilation periods determined by MDR pathogens. Infectious complications in burned patients have caused $42-65 \%$ of deaths in the last 10 years. It is of critical importance to comprehend that MDR infections present further risk factors and therefore to develop preventive strategies in severely burned patients [5,11-14].

\section{INFECTIOUS SYNDROMES IN BURN PATIENTS}

Major burn injuries are unique compared to other traumatic causes, due to the severity of the systemic impact that can persist even several years after the injury. An important inflammatory response is generated

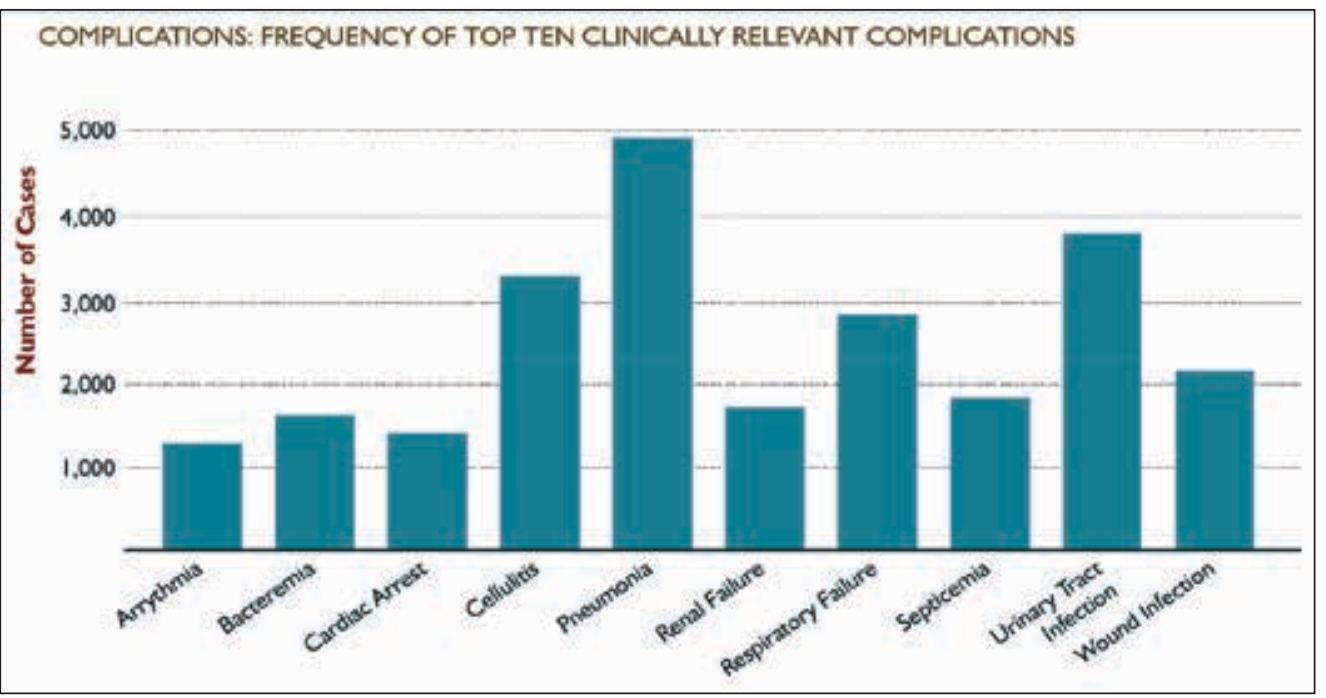

FIGURE 1. Distribution of complications in the 208,654 burn patients included in "The 2017 National Burn Repository Report" of ABA (9) 


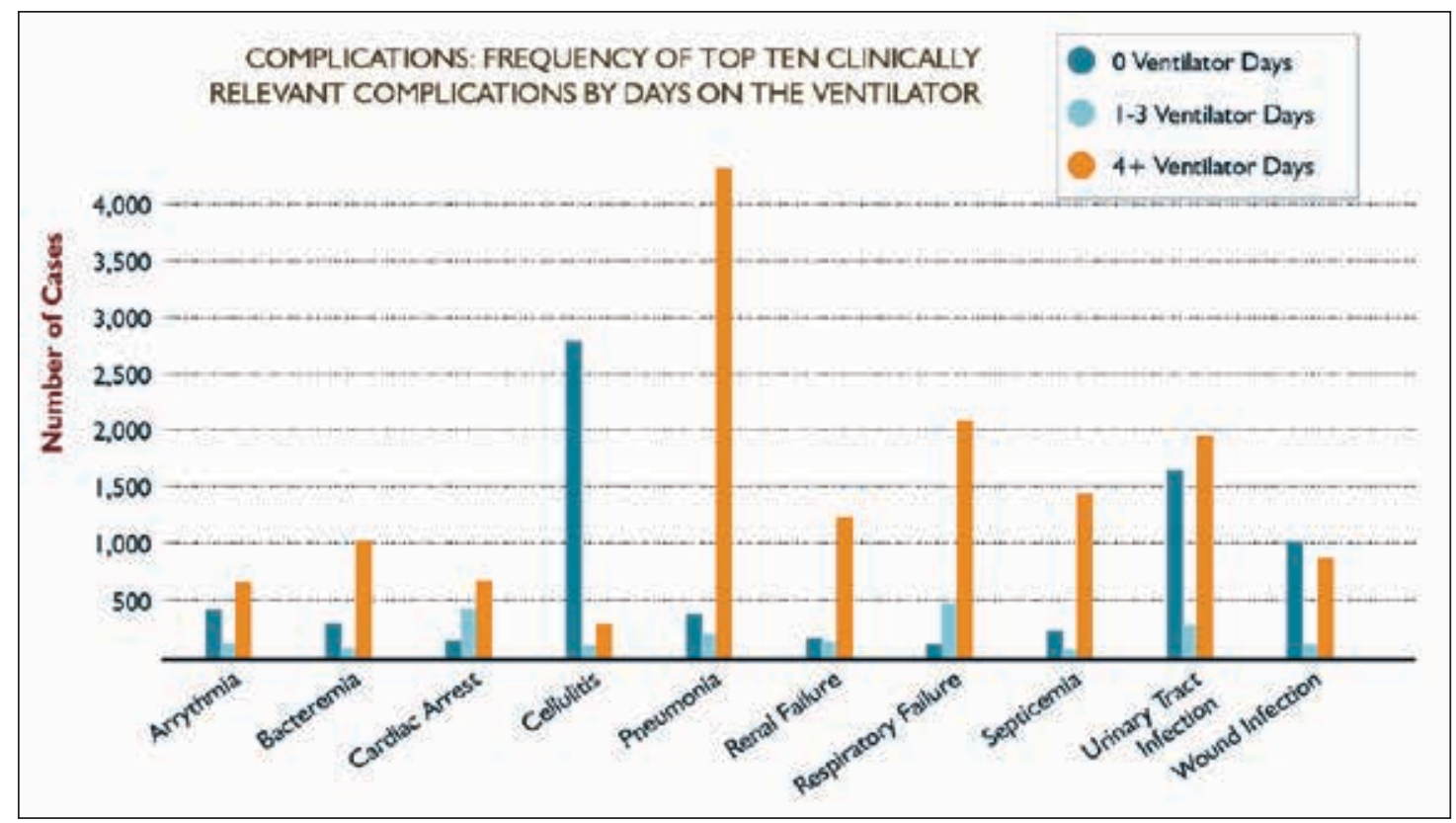

FIGURE 2. Association between burn complications and duration of mechanical ventilation - adapted after (9)

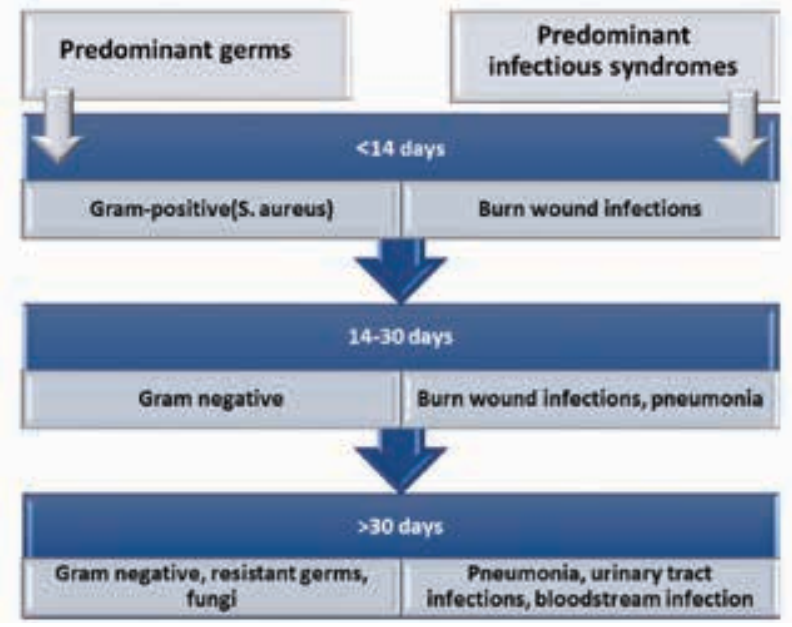

FIGURE 3. Dynamic of the infectious complications during patient hospitalization

as response to burn injury, known as hypermetabolic response, characterized by catabolic state, immunologic alterations, infections, with subsequent multiple organ failure and death $[3,15]$. Infectious complications in those immunosuppressed hosts are caused by external pathogens but also from their own microbiota(encountered on skin, airways and gastrointestinal tract), presenting as different clinical syndromes, frequently associated in the same patient $[8,14]$.

\section{Burn wound infections}

Burn wounds represents an optimal environment for bacterial growth due to altered vascularization and presence of devitalized tissue. Diagnosis of burn wound infection can be challenging because the usual cytokine cascade and inflammation are similar with infection presence and clinical signs, as tachycardia or fever, are typically encountered in burns physiopathology $[5,14,16]$.

Clinical findings(the wound aspect and smell alteration) can be useful in orienting differential diagnosis between colonization and infection of the burn wound. Microbiological testing of the burn wound sites is mandatory for determining the specific pathogen and guidance of the burn wound treatment $[8,14]$.

Kwei et al. have shown three main ways of sampling the burn wound: qualitative (the presence or absence of bacteria development), semi-quantitative (assessing the bacteria quantity as being scanty, few, moderate or numerous) and quantitative (establishing an absolute quantity) [17].

In severely burned patients, the wound becomes colonized at five to seven days after the burn infliction. Burn wound colonization is characterized by low bacterial concentration, microbial load $<10^{5}$ germs/g tissue, without invasive infection $[8,14]$. The objective diagnosis of burned wound infection are realized by wound biopsy (microbial load $10^{5} \mathrm{CFU} / \mathrm{g}$ tissue) [8].

Additionally to burn wound surface and tissue cultures, patients presenting signs of systemic infections ought to have a full septic workup that involves blood and urine cultures as well as burn wound sample cultures. Adequate treatment of burn wound infections implies an adequate surgical treatment, a high number of burn wound dressing changes with maximization of the patient's antimicrobial treatment according to microbiology culture and susceptibility results from burn wound cultures $[5,8,18]$.

A series of clinical presentations can be encountered for burn wound infections, classified as follows $[8,14,19]$ : 
1. Burn wound impetigo - implies the loss of epithelium from an anteriorly epithelialized area, such as grafted burns, partial-thickness burns meant to heal by secondary intention, or already healed donor areas.

2. Cellulitis - is another type of burn wound infection that should be differentiated from burn wound erythema. The erythema surrounding the burn wound is a sterile physiological process resulted from the local inflammatory markers produced in the area adjacent to the burn wound; typically, this inflammation sign appears in the first 2-3 days from the burn injury and it generally resolves in a week from that moment. The best differential diagnostic is established by performing the clinical examination, mainly by palpating - the erythema is not indurated and presents no fluctuance in comparison to an infectious process like cellulitis. Burn wound cellulitis appears as expansion of erythema beyond the injury margins into the healthy, intact skin and soft tissues adjacent to the burn wound, with at least one of the following factors being present: local pain, inflammation or high temperature at the affected site, advancement of erythema and inflammation, and lymphangitis and/or lymphadenitis expanding from the affected skin surface along the paths of lymphatic drainage to the area.

3. Invasive infection in unexcised burn wounds - Patients with surfaces of unexcised deep partial-thickness or full-thickness burn wound have a higher risk of acquiring an invasive infection, with following findings: a rapid associated change in burn wound aspect or character such as separation of the eschar or dark brown, black, or violaceous color of the eschar, inflammation of the adjacent healthy skin with edema, erythema, high local temperature, local pain and proof of microbial invasion into surrounding healthy tissue on histological evaluation, also positive blood cultures with evidence of a pathogen's presence, in the absence of another determinable cause of infection and systemic signs of sepsis.

4. Burn-related surgical wound infection - involves both excised burn wounds and donor areas that have not epithelialized so far. The wound presents a purulent secretion that is positive for cultures.

Regarding the presence of specific pathogens, the burned wound is characterized in the early period by colonization with gram positives as Group A Streptococcus which can associate fever, cellulitis, lymphangitis. Another frequent pathogen is Staphylococcus aureus, with a less aggressive pattern $[5,8]$. Severe infection in this period can be caused by Clostridium spp., when extensively devitalized tissue is present, like in electrical injuries, with manifestations as crepitation, sepsis and myonecrosis [20].

In contrast, after day five, gram negatives become prevalent in burned wounds. By second week of im- proper surgical management, germs penetrate the eschar by creating a sloughing environment due to lytic processes and spread through all systems [8,14,21].

Fungal wound infections, although long time underestimated, become increasingly common after intensive usage of topical and systemic broad-spectrum antibiotics, with pathogens as Candida spp. and filamentous fungi as Aspergillus, Fusarium, Mucor and Rhizopus. Also, viral infections can be encountered in severely burned patients, requiring specific antiviral treatment $[8,14,21]$.

Table 1 synthetizes the characteristics of frequently encountered pathogens in severely burned patients and also the current recommended treatment from international guides $[5,14]$.

Burn injury may involve important functional areas in which the onset of infections leads to increased morbidity with impaired functional prognosis [8]. Facial burn lesions require a careful assessment and treatment (a clinical case is illustrated in figure 5). A particular situation is represented by the periocular area burn lesions, caused by either thermal, electrical or chemical agents which may lead to severe vision impairment. Also, in patients presenting extensive facial and eyelids burns without initial ocular globe injury, secondary severe lesions may appear as result of impossibility to eyelid closure with corneal exposure, ulceration and development of infections [22,23]. Deep burn injuries involving auricular region may lead to infection of the ear cartilage. Chondritis develops due to the poor vascularization of the cartilage and it is difficult to treat requiring antibiotic treatment combined with serial debridement, drainage and large excision of necrotic tissue [14].

Another particular anatomic region is represented by the perineal area, which also associates a high risk in developing burn wound infections because of the presence of local moisture and fecal exposure, requiring careful preventive measures, patient monitoring and prompt therapeutic treatment of infectious complications $[24,25]$.

Currently, the standard of care of the full thickness burn wounds is represented by the early excision and coverage with autologous skin grafts(if autografting is not possible, skin substitutes may be used). Early excision reduces infections risk, duration of hospitalization, morbidity and mortality (mortality is decreased with excision and grafting in burn injuries unassociated with inhalation injury) [26-28]. It has been shown by Barret and Herndon that early excision can reduce the pathogen number from more de 100,000 pathogens/g to less than 10,000 pathogens/g and ensure a good graft integration. However, for the patients with more than $1,000,000$ pathogens/g, after the surgical treatment, the number has lowered to less than 10,000 patho- 
TABLE 1. Burn wound pathogens

\begin{tabular}{|c|c|c|c|}
\hline $\begin{array}{l}\text { PATHOGEN } \\
\text { TYPE }\end{array}$ & NAME & CHARACTERISTICS & $\begin{array}{l}\text { RECOMMENDED TREATMENT } \\
\text { (IDEAL: ANTIBIOGRAM GUIDED!) }\end{array}$ \\
\hline \multirow[t]{7}{*}{ BACTERIA } & Staphylococcus aureus & $\begin{array}{l}\text { Gram positive coccus opportunistic } \\
\text { - Most common infections: sepsis, } \\
\text { cellulitis, impetigo, scalded skin } \\
\text { syndrome, postoperative wound } \\
\text { infections. MRSA > 50\% in burn units. }\end{array}$ & $\begin{array}{l}\text { Vancomycin IV or Trimethoprim- } \\
\text { sulfamethoxazole and Rifampin orally }\end{array}$ \\
\hline & Streptococci spp. & $\begin{array}{l}\text { Gram positive coccus. Major infecting } \\
\text { species: S. pyogenes and S. agalactiae. }\end{array}$ & $\begin{array}{l}\text { Penicillin } \mathrm{G} \text { and Penicillin } \mathrm{V} \text { and } 1 \text { st } \\
\text { generation cephalosporins }\end{array}$ \\
\hline & Pseudomonas aeruginosa & $\begin{array}{l}\text { Gram negative. Primary sources: local } \\
\text { and translocation of gastrointestinal } \\
\text { flora. }\end{array}$ & $\begin{array}{l}\text { Piperacillin/Tazobactam, Cefepime and } \\
\text { carbapenems. For MDR P. aeruginosa: 5th } \\
\text { generation cephalosporins and colistin. }\end{array}$ \\
\hline & Acinetobacter spp. & $\begin{array}{l}\text { Gram negative rods opportunistic, } \\
\text { predisposition for infecting patients with } \\
\text { dysfunctional host defense mechanisms. }\end{array}$ & $\begin{array}{l}\text { Carbapenems (e.g. imipenem and } \\
\text { meropenem). For MDR Acinetobacter: } \\
\text { colistin. }\end{array}$ \\
\hline & $\begin{array}{l}\text { Stenotrophomonas } \\
\text { maltophilia }\end{array}$ & $\begin{array}{l}\text { Aerobic gram-negative bacillus, very } \\
\text { difficult to eradicate because of the } \\
\text { highly obturant biofilm that it creates. }\end{array}$ & $\begin{array}{l}\text { Trimethoprim-sulfamethoxazole }+/- \\
\text { Levofloxacin along with soap and water } \\
\text { lavage }\end{array}$ \\
\hline & $\begin{array}{l}\text { Enterobacteriaceae (E. coli, } \\
\text { Klebsiella spp., Enterobacter } \\
\text { spp., Serratia marcescens } \\
\text { and Proteus spp.) } \\
\end{array}$ & Gram negative & $\begin{array}{l}\text { Carbapenems - lately increasing resistance } \\
\text { leads to Colistin requirement. }\end{array}$ \\
\hline & $\begin{array}{l}\text { Bacteroides spp. and } \\
\text { Fusobacterium spp. }\end{array}$ & $\begin{array}{l}\text { Anaerobic bacteria, rarely a cause of } \\
\text { invasive burn infection. Normal flora } \\
\text { from oropharyngeal cavity to the GI } \\
\text { tracts. Usually, associated to avascular } \\
\text { myonecrosis due to electrical burns, } \\
\text { frostbite or thermal burns with crush } \\
\text { mechanism. }\end{array}$ & Broad-spectrum antibiotics \\
\hline FUNGI & $\begin{array}{l}\text { Candida spp., Aspergillus } \\
\text { spp., Penicillium spp., } \\
\text { Rhizopus spp., Mucor spp., } \\
\text { Rhizomucor spp., Fusarium } \\
\text { spp., Curvularia spp. }\end{array}$ & $\begin{array}{l}\text { Increasing prevalence after use of topical } \\
\text { agents and free use of broad-spectrum } \\
\text { antibiotics; immunosuppressed status of } \\
\text { the patient. }\end{array}$ & $\begin{array}{l}\text { Topical treatment if multiple sites infected, } \\
\text { and systemic treatment if invasive infection } \\
\text { such as } 6,000,000 \mathrm{U} / \mathrm{g} \text { Nystatin. }\end{array}$ \\
\hline \multirow[t]{3}{*}{ VIRAL } & HSV & $\begin{array}{l}\text { The most common cause of } \\
\text { viral infection is reactivation of } \\
\text { latent infection because of the } \\
\text { immunodeficiency present in burn } \\
\text { patients. }\end{array}$ & Acyclovir /Valacyclovir IV. \\
\hline & VZV & $\begin{array}{l}\text { They are more common in pediatric } \\
\text { patients. }\end{array}$ & Acyclovir \\
\hline & CMV & $\begin{array}{l}\text { It appears associated to bacterial and } \\
\text { fungal infections, but it only seldom has } \\
\text { any influence on the clinical outcome. }\end{array}$ & $\begin{array}{l}\text { Acyclovir IV/longer acting oral prodrug } \\
\text { Valacyclovir/Ganciclovir/Valganciclovir oral } \\
\text { therapy of choice. }\end{array}$ \\
\hline
\end{tabular}
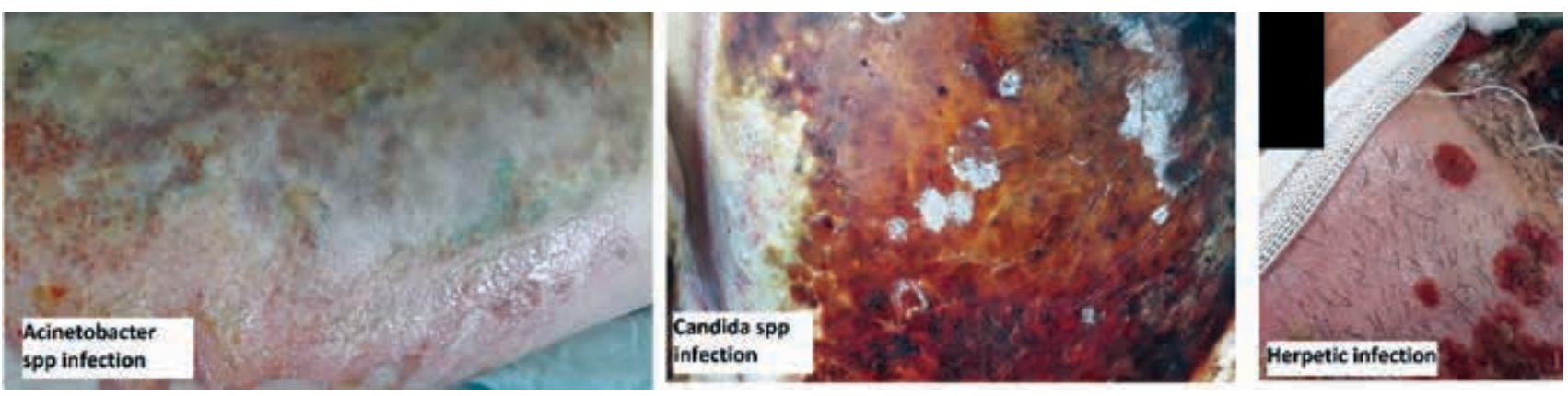

FIGURE 4. Clinical presentation of various pathogens infections in burned patients 
FIGURE 5. Extensive facial burns in a 48 year old male patient involving also periorbital area and external ear region with auricle necrosis requiring amputation; burn wound excision and skin grafting were performed

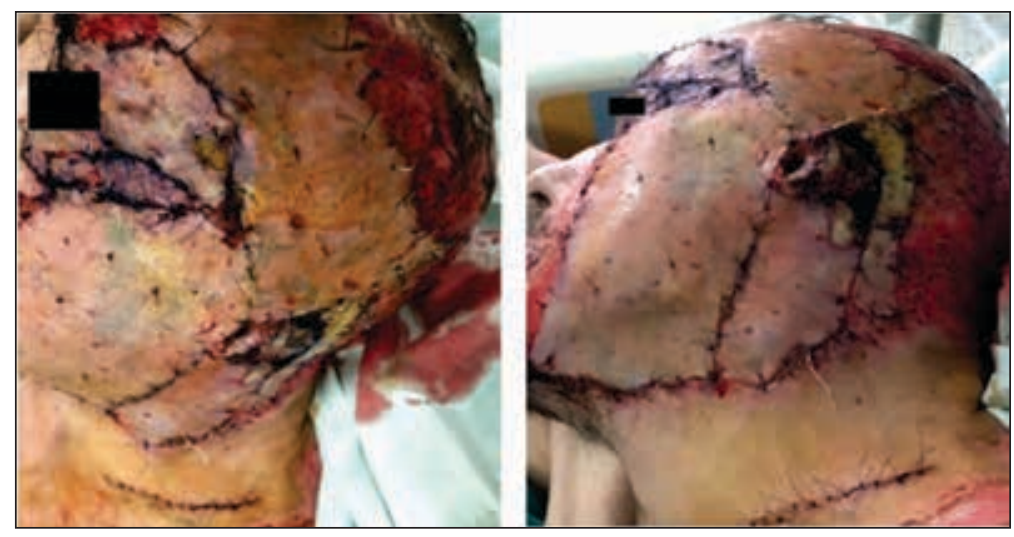

FIGURE 6. Extensive fascial excision and splitthickness skin grafting in a 41-year-old male patient who suffered flame injury with deep burns on 55\% TBSA. Multidrug resistant Acinetobacter spp. was isolated in the burn wounds; according to antibiogram, Colistin was administered.

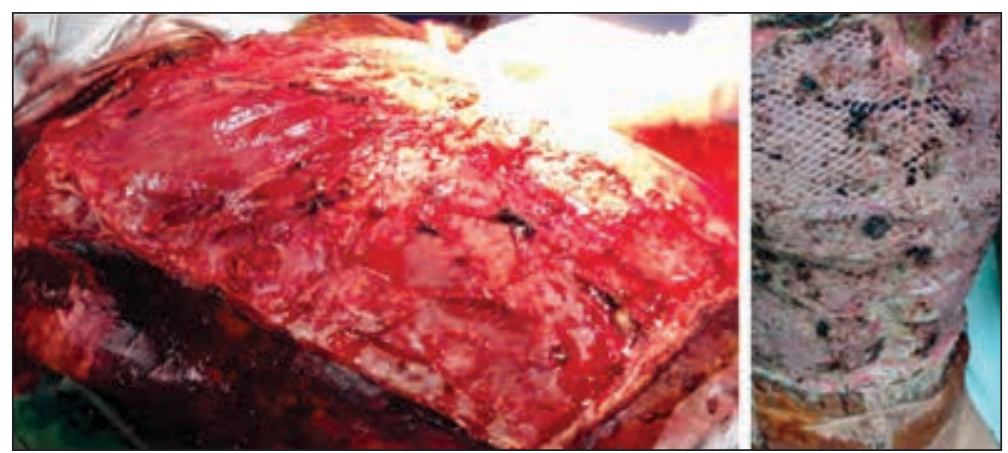

gens/g, but with a worse graft integration rate. Even for highly resistant pathogens provoking severe infections, aggressive, surgical excision proved to be efficient in infection control (figure 6-clinical case example) $[14,29]$.

For patients with partial-thickness lesions, topical antiseptic and antimicrobial agents are recommended for burn care, depending on wound and patient characteristics; the use of topical antimicrobial agents for burned injuries also led to a significant decrease of mortality in those patients [14].

\section{Respiratory tract infections}

Infections of the respiratory tract are the most often reported by the burn centers [6]. Pulmonary infectious complications are a major trigger of septic death after burn injury and can be divided into ventilator hospital-acquired pneumonia (V-HAP) and non-ventilator hospital-acquired pneumonia (NV-HAP). The first occurs 48 to 72 hours after endotracheal intubation and mechanical ventilation, while the latter usually appears due to bloodstream dissemination [30,31].

Analyzing the causal correlation between burn injury and pneumonia, the general rational hypothesis is that patients suffering from burn injuries have an increased risk of developing different forms of pneumonia. Risk factors include altered immune function, face and neck burns, inhalation injury, edema, previous comorbidities [31]. Other risk factors include atelectasis, decreased lung expansion due to hyperventilation in ventilated patient, restrictive syndrome due to circumferential eschar formation, as well as occurrence of aspiration episodes [8]. Increased hospitalization length and duration of mechanical ventilation associate with the risk of ventilator acquired pneumonia development [32]. Patients that present with inhalation injury usually have a high TBSA. In addition to that, TBSA itself is directly correlated with development of acute respiratory distress syndrome (ARDS) another risk factor that may cause pneumonia [31].

Diagnosis of pneumonia in burned patients consists of two of the following three criteria, the first being a chest radiographic change such as infiltrate, capitation or consolidation, the second consists of sepsis as defined in burned patients and the third criteria is represented by modification of sputum characteristics: color, quantity, consistency and purulence $[5,14]$.

Nosocomial pneumonia in the burn intensive care unit usually occurs with antibiotic resistant pathogens, prevalence ranging from $10-65 \%$ with overall mortality over $25 \%$; over $10^{4} \mathrm{CFU} / \mathrm{ml}$ is enough to diagnose V-HAP $[8,32,33]$. When pathogens are the same as those from the wound, the phenomenon is considered cross-contamination [8]. Bioluminescence rapid bacterial adenosine triphosphate (ATP) assay has been demonstrated to perform excellent when compared to quantitative culture tests. This may allow physicians to prescribe antibiotics faster for patients with a positive screening assay [8]. Microscopic analysis and cultures of endotracheal aspirate or sputum are recommended. 
Blood cultures should also be drawn before antibiotic therapy is initiated in patients with fever, to detect bacteremia. If bacteremia is present, empirical systemic antibiotics should be administered guided by the most recent cultures results taken from either sputum, urine or wound bed with further therapy adjustment after obtaining the antibiograms [8].

\section{Gastrointestinal infections}

Large burns may cause severe fluid loss leading to systemic hypoperfusion. The mucosa of the gastrointestinal tract is therefore altered, mainly due to sloughing. Clinical changes such as abdominal bloating, watery stools and dampened intestinal sounds are therefore noticeable. Diarrhea is no exception, and testing for $C$. difficile, a frequent pathogen of patients suffering from large burns should be mandatory, especially if the patient is immunocompromised or if multiple antibiotics were administered throughout the management history. The most impactful complication of such infection is death due to fulminant toxic colitis or intestinal perforation [14].

\section{Urinary tract infections}

Urinary tract infections occur due to two main causes in patients with burn wounds, the first being usage of urinary catheter and hematogenous inoculation. Most often, fungi were noted to be present in urinary cultures due to prolonged and needless usage of catheters. In patients presenting perineal and genital burns, catheters may be left in place for extended periods. If infection is suspected, urine should be cultured, the catheters are exchanged or removed if possible, followed by initiation of empirical antibiotic, then targeted therapy according to antibiogram results $[8,14]$.

\section{Catheter infections and suppurative thrombophlebitis}

Infections having as source intra-arterial or intravenous catheters can be encountered in the burn unit, literature reporting such complications in a range between $8 \%$ and $57 \%$ of burned patients [8].

Suppurative thrombophlebitis is suspicioned in burn patients with positive blood cultures, without an evident source of infection, as in many patients the infected vein may not be identified at clinical examination; endocarditis should be excluded [8,14]. Without an adequate treatment(antibiotherapy and surgical intervention for excision of the affected vein and local debridement), severe complications may develop including sepsis, endocarditis or septic embolization in various organs) $[8,14]$.

\section{Sepsis in burn patients}

Tissue damage because of severe burns results in discharge of immune cells, including monocytes, mac- rophages and neutrophils within a few hours from the burn infliction. These cells recognize endogenous factors such as damage-associated molecular patterns (DAMPs) or alarmins that are produced as result of burn-mediated tissue damage. DAMPs and their exogenous complements, pathogen-associated molecular pattern molecules (PAMPs), are identified via pattern recognition receptors, namely Toll- like receptors (TLRs) and NOD- like receptors (NLRs). The ligation of TLRs and NLRs to their specific ligands leads to the activation of inflammatory cascades, resulting into activation of NF-KB, a master transcription factor implicated in the discharge of numerous inflammatory mediators (such as IL-1, IL-6, IL-8, IL-18 and TNF) $[3,16]$. The discharge of these cytokines and chemokines facilitates the cycle of inflammation provoking the systemic inflammatory response syndrome (in which uncontrolled cytokine discharge draws in excessive leukocyte recruitment, fever or hypothermia, tachycardia, and tachypnoea). The inflammatory response can lead to immunosuppression and inefficient response to bacterial invasion [3]. That involves immune functions such as macrophage antigen presentation or neutrophil killing of invading pathogens that are highly compromised. Furthermore, T cell proliferation and IL-2 production are suppressed as well. Metabolic changes imply enhanced muscle protein destruction, insulin resistance and augmented cardiac load $[3,15,34]$. The apex of these processes is generally the systemic inflammatory response syndrome (SIRS), an inflammatory status affecting the entire body, which can result into multiple organ insufficiency, and finally, death [3].

Figure 7 describes the mechanism of inflammatory response, sepsis and development of multiple organ failure in severely burned patients.

In 2007, the American Burn Association has defined sepsis as a documented infection (positive cultures or germ identified at histological testing or therapeutic response to antimicrobials) along with 3 out of 6 of the following criteria: tachypnea, tachycardia, hypo/hyperthermy, hyperglycemia, thrombocytopenia, and impossibility to enteral feeding for more than one day. Additionally, they have concluded that the best criteria to diagnose multiple organ dysfunction syndrome (MODS) is represented by modified Marshall scoring system [35].

If sepsis is documented, an aggressive antibiotic treatment is immediately started, which will then be de-escalated when establishing the definitive diagnosis, also depending on the patient's clinical response [14].

\section{PRINCIPLES OF ANTIBIOTIC THERAPY IN BURNED PATIENTS}

According to multiple studies the prophylactic systemic antibiotic administration in severely burned pa- 


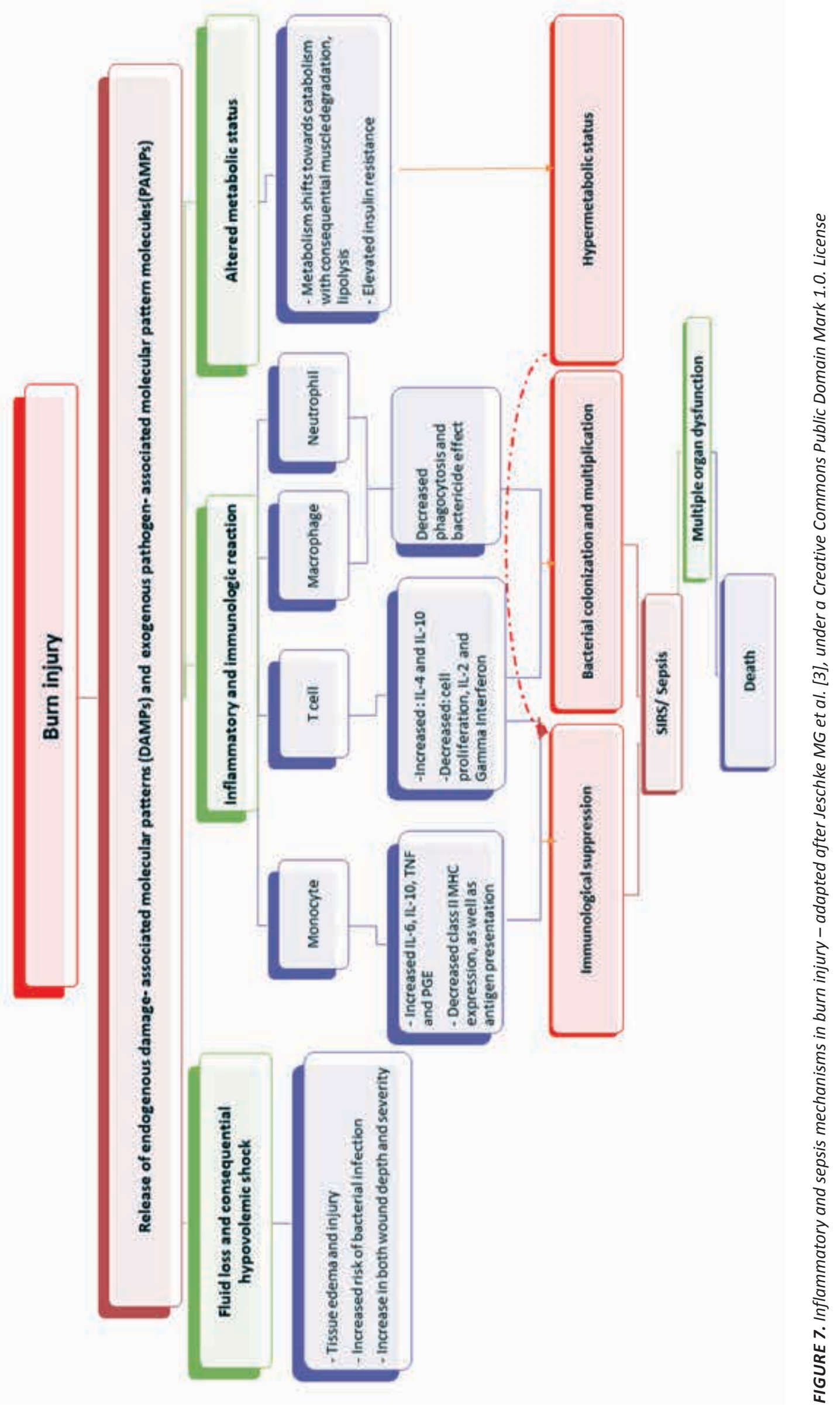


tients has proven to be inefficient, therefore international societies do not recommend antibiotic prophylaxis in burn care, only perioperative antibiotic administration being promoted when infections are not documented $[6,8,36]$.

The modern protocols of infection prevention have proven to be efficient in avoiding the installation of new pathogens, that may also be antibiotic-resistant, in the burn unit's nosocomial flora. These protocols have also prevented reseeding these strains from patients in neighboring wards $[6,8,37]$.

However, the development of new antibiotics is slower than the pathogen agents' capability to acquire antibiotic resistance. It is crucial to note that early excision of the tissues that are infected, wound grafting and application of topical antimicrobials are the only efficient treatment, if antibiotic treatment is not efficient for a certain pathogen. Additionally, aggressive debridement of tissue detritus must become a regular activity for patients with burn wounds $[6,8,38]$. Just like there is a recommendation for burn eschar excision in case of profound soft tissue infection or cellulitis, there is also a recommendation for early removal of an infected catheters, particularly in infections determined by pathogens that produce biofilm $[6,8]$.

The antibiotherapy is administered guided by antibiogram results, but if needed, when clinical and paraclinical signs are suggestive for an infection, the antibiotherapy is started empirically, with broad spectrum agents and immediately after the antibiogram is available, targeted antibiotic is introduced. De-escalation principle is applied, in order to administer the drug effective on found germs but with a narrow spectrum and if possible, to avoid the reserve antibiotics. An important aspect is the high-level microbial resistance observed in many countries $[6,8,14,39,40]$. Burn unit specific local flora represent another important element when guiding empirical therapy, therefore it is necessary to perform regular testing in patients and also in wards and administrative spaces of the burn center [6].

A key element is to promote in the burn center an antimicrobial stewardship program, with multidisciplinary involvement of the plastic surgeon, anesthesiologist and infectious disease doctor in order to ensure best clinical outcome for the patient and reduce further development of resistant germs [6].

\section{CONCLUSIONS}

Improved outcomes for severely burned patients have been attributed to continuous medical advances in fluid resuscitation, nutritional and immunological support, pulmonary and burn wound care and infection control practices. Infections represent the most frequent and severe complication in major burned patients and requires appropriate diagnosis and treatment. Infection is triggered by loss of natural skin barrier in addition to the disturbed immune function with subsequent immunosuppression, inhalation injury, vascular access, intubation and urinary catheterization.

Recent improvements in critical care, ensuring high-level systemic support of the burn patient, standardized surgical protocols along with progresses in antimicrobial therapy contribute to a significant burn morbidity and mortality reduction and improved functional outcome.

The main factors involved in infectious prevention in burned patients are represented, however, by thorough infection control protocols, early excision and coverage of the deep burned lesions, frequent clinical monitorization as well as harvesting microbial samples on a routine basis and prompt treatment when an infection is documented.

Conflict of interest: none declared

Financial support: none declared

\section{REFERENCES}

1. World Health Organization. Burns. Available at: WHO https://www.who.int/en/news-room/ fact-sheets/detail/burns.

2. Greenhalgh DG. Management of Burns. $N$ Engl J Med. 2019 Jun 13;380(24):2349-2359.

3. Jeschke MG, van Baar ME, Choudhry MA, Chung KK, Gibran NS, Logsetty S. Burn injury. Nat Rev Dis Primers. 2020;6(1):11.

4. Hettiaratchy S, Dziewulski P. ABC of burns: pathophysiology and types of burns [published correction appears in BMJ. 2004 Jul 17;329(7458):148]. BMJ. 2004;328(7453):1427-1429.

5. Norbury W, Herndon DN, Tanksley J, Jeschke MG, Finnerty CC. Infection in Burns. Surg Infect (Larchmt). 2016;17(2):250-255.
6. Lachiewicz AM, Hauck CG, Weber DJ, Cairns BA, van Duin D. Bacterial Infections After Burn Injuries: Impact of Multidrug Resistance. Clin Infect Dis. 2017; 65(12):2130-2136.

7. American Burn Association. Burn Incidence and Treatment in the United States, 2016. Available at: https://ameriburn.org/who-weare/media/burn-incidence-fact-sheet/.

8. Church D, Elsayed S, Reid O, Winston B Lindsay R. Burn wound infections. Clin Microbiol Rev. 2006;19(2):403-434

9. American Burn Association. National Burn Repository 2017. Version 13.0. Available at: https://ameriburn.site-ym.com/.

10. Dries DJ, Marini JJ. Management of Critical Burn Injuries: Recent Developments. Korean J Crit Care Med. 2017;32(1):9-21.
11. Vinaik R, Barayan D, Shahrokhi S, Jeschke MG. Management and prevention of drug resistant infections in burn patients. Expert Rev Anti Infect Ther. 2019;17(8):607-619.

12. van Langeveld I, Gagnon RC, Conrad PF, Gamelli RL, Martin B, Choudhry MA, Mosier MJ. Multiple-Drug Resistance in Burn Patients: A Retrospective Study on the Impact of Antibiotic Resistance on Survival and Length of Stay. J Burn Care Res. 2017 Mar/Apr;38(2):99-105.

13. Powers JH. Development of drugs for antimicrobial-resistant pathogens. Curr Opin Infect Dis. 2003 Dec;16(6):547-51.

14. Cambiaso-Daniel J, Gallagher JJ, Norbury WB, FinnertyCC, Herndon DN, Culnan DM. Treatment of Infection in Burn Patients. In 
Herndon DN (ed.). Total Burn Care (Fifth Edition). Elsevier, 2018:93-113.

15. Nielson CB, Duethman NC, Howard JM, Moncure M, Wood JG. Burns: Pathophysiology of Systemic Complications and Current Management. J Burn Care Res. 2017;38(1):e469-e481.

16. Strudwick XL, Cowin AJ. The Role of the Inflammatory Response in Burn Injury. In: Kartal SP, Bayramgürler D. Hot Topics in Burn Injuries. IntechOpen. 2017. Available at: https://www.intechopen.com/books/ hot-topics-in-burn-injuries/the-role-of-theinflammatory-response-in-burn-injury.

17. Kwei J, Halstead FD, Dretzke J, Oppenheim BA, Moiemen NS. Protocol for a systematic review of quantitative burn wound microbiology in the management of burns patients. Syst Rev. 2015;4:150.

18. Duane T, Young A. Hospital Infection Control-Burns. In: Infectious Disease Advisor. Available at: https://www. infectiousdiseaseadvisor.com.

19. Mayhall CG. The epidemiology of burn wound infections: then and now. Clin Infect Dis. 2003 Aug 15;37(4):543-50.

20. Teodoreanu R, Popescu SA, Lascar I. Electrical injuries. Biological values measurements as a prediction factor of local evolution in electrocutions lesions. $\mathrm{J} \mathrm{Med}$ Life. 2014;7(2):226-236.

21. Cancio LC, Howard PA, McManus AT, et al. Burn wound infections. In: Holzheimer RG, Mannick JA, editors. Surgical Treatment: Evidence-Based and Problem-Oriented. Munich: Zuckschwerdt; 2001.

22. Capek KD, Culnan DM, Merkley K, Huang TT, Trocme S. Burn Injuries of the Eye. In Herndon DN (Ed.). Total Burn Care (Fifth Edition). Elsevier, 2018:435-444.

23. Bates A, Zanaboni A. Ocular Burns [Updated 2020 Aug 10]. In: StatPearls [Internet]. Treasure Island (FL): StatPearls Publishing; 2021.
24. Bordes J, Le Floch R, Bourdais L, Gamelin A, Lebreton F, Perro G. Perineal burn care: French working group recommendations. Burns. 2014 Jun;40(4):655-63.

25. Clemens MS, Janak JC, Rizzo JA, Graybill JC, Buehner MF, Hudak SJ, Thompson CK, Chung KK. Burns to the genitalia, perineum, and buttocks increase the risk of death among U.S. service members sustaining combat-related burns in Iraq and Afghanistan. Burns. 2017 Aug;43(5):11201128.

26. Zuo KJ, Medina A, Tredget EE. Important Developments in Burn Care. Plast Reconstr Surg. 2017 Jan;139(1):120e-138e.

27. Ong YS, Samuel M, Song C. Meta-analysis of early excision of burns. Burns. 2006;32(2):145-50.

28. Rowan MP, Cancio LC, Elster EA, et al. Burn wound healing and treatment: review and advancements. Crit Care. 2015;19:243.

29. Barret JP, Herndon DN. Effects of burn wound excision on bacterial colonization and invasion. Plast Reconstr Surg. 2003 Feb;111(2):744-52.

30. Eckert MJ, Wade TE, Davis KA, Luchette FA, Esposito TJ, Poulakidas SJ, Santaniello JM, Gamelli RL. Ventilator-associated pneumonia after combined burn and trauma is caused by associated injuries and not the burn wound. J Burn Care Res. 2006 Jul-Aug;27(4):457-62.

31. Chan $\mathrm{CH}$, Yang SF, Yeh HW, Yeh YT, Wang $\mathrm{YH}$, Teng $\mathrm{YH}$, Yeh CB. Risk of pneumonia in patients with burn injury: a population-based cohort study. Clin Epidemiol. 2018;10:10831091.

32. Wu D, Wu C, Zhang S, Zhong Y. Risk Factors of Ventilator-Associated Pneumonia in Critically III Patients. Front Pharmacol. 2019;10:482.

33. Latenser BA, Miller SF, Bessey PQ, Browning SM, Caruso DM, Gomez M, Jeng JC, Krichbaum JA, Lentz CW, Saffle JR,
Schurr MJ, Greenhalgh DG, Kagan RJ. National Burn Repository 2006: a ten-year review. J Burn Care Res. 2007 Sep-Oct; 28(5):635-58.

34. Fazal N. T Cell Suppression in Burn and Septic Injuries. In: Kapur S, Portela MB Immunosuppression - Role in Health and Diseases, IntechOpen, 2012. Available at: https://www.intechopen.com/books/ immunosuppression-role-in-health-anddiseases/t-cell-suppression-in-burn-andseptic-injuries.

35. Greenhalgh DG, Saffle JR, Holmes JH 4th, Gamelli RL, Palmieri TL, Horton JW, Tompkins RG, et al.; American Burn Association Consensus Conference on Burn Sepsis and Infection Group. American Burn Association consensus conference to define sepsis and infection in burns. J Burn Care Res. 2007 Nov-Dec;28(6):776-90.

36. Ramos G, Cornistein W, Cerino GT, Nacif G. Systemic antimicrobial prophylaxis in burn patients: systematic review. J Hosp Infect. 2017 Oct;97(2):105-114.

37. Weber J, McManus A; Nursing Committee of the International Society for Burn Injuries. Infection control in burn patients. Burns. 2004 Dec;30(8):A16-24.

38. Dai T, Huang YY, Sharma SK, Hashmi JT, Kurup DB, Hamblin MR. Topical antimicrobials for burn wound infections. Recent Pat Antiinfect Drug Discov. 2010;5(2):124-151.

39. Nunez Lopez O, Cambiaso-Daniel J, Branski LK, Norbury WB, Herndon DN. Predicting and managing sepsis in burn patients: current perspectives. Ther Clin Risk Manag. 2017;13:1107-1117.

40. European Centre for Disease Prevention and Control. Antimicrobial resistance. Available at: https://www.ecdc.europa.eu/en/ antimicrobial-resistance. 